https://artnodes.uoc.edu

\title{
Tecnologías de fabricación digital de bajo coste aplicadas a la construcción de esculturas de gran formato
}

\author{
Drago Díaz-Alemán \\ Universidad de La Laguna (España) \\ Cecile Meier \\ Universidad de La Laguna (España) \\ Itahisa Pérez-Conesa \\ Universidad de La Laguna (España) \\ Esteban Amador-García \\ Universidad de La Laguna (España)
}

Fecha de presentación: septiembre de 2020

Fecha de aceptación: marzo de 2021

Fecha de publicación: julio de 2021

\section{Cita recomendada}

Díaz-Alemán, Drago; Meier, Cecile; Pérez-Conesa, Itahisa; Amador-García, Esteban. 2021. «Tecnologías de fabricación digital de bajo coste aplicadas a la construcción de esculturas de gran formato». Artnodes, núm. 28. UOC. [Consulta: dd/mm/aa]. http://doi.org/10.7238/a. v0i28.373923

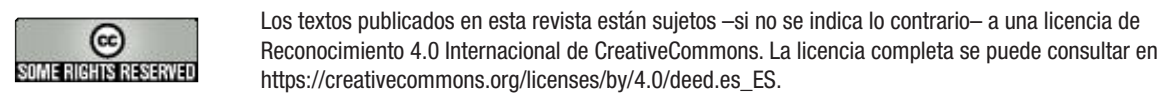

\section{Resumen}

La creación escultórica suele ser una labor artística que implica técnicas manuales que se siguen trabajando de manera tradicional mediante modelado de esculturas con arcilla y su conversión en materiales duraderos mediante moldes. Esta técnica implica habilidades escultóricas y una gran inversión en materiales, tiempo y la ayuda de maquinaria u otras personas. Con la aparición de las tecnologías tridimensionales, estos procesos se pueden acelerar, aligerar y abaratar de 


\title{
artnodes
}

https://artnodes.uoc.edu

Tecnologías de fabricación digital de bajo coste aplicadas a la construcción de esculturas de gran formato

manera significativa, aunque es necesario disponer de maquinaria costosa. Esta propuesta pretende combinar las tecnologías de bajo coste con las técnicas tradicionales para crear esculturas de gran formato. Primero se procede a la digitalización tridimensional y el modelado 3D de tres estatuillas, pertenecientes al arte cicládico, y se construye la forma bruta mediante el apilamiento de planchas de espuma cortados con una fresadora. A continuación, se trabaja la escultura hasta conseguir la forma definitiva. Por último, se describen tres procedimientos que se han utilizado para convertir las esculturas en un material definitivo. Se realiza una escultura mediante llenado macizo, otra se llena a dos mitades para conseguir una obra hueca y, por último, se aplica el cemento directamente sobre las planchas de espuma, de forma que se elimina la necesidad de molde.

\section{Palabras clave}

escultura de gran formato, ampliación, tecnologías 3D, digitalización, bajo coste

\section{Low-cost digital manufacturing technologies applied to the construction of large-format sculptures}

\begin{abstract}
Sculptural creation is usually an artistic task that involves manual techniques that are still worked in the traditional way by modelling sculptures with clay and converting them into durable materials by means of moulds. This technique involves sculptural skills and a large investment in materials, time and the help of machinery or other people. With the advent of three-dimensional technologies, these processes can be accelerated, made lighter and significantly cheaper, although expensive machinery is required. This proposal aims to combine low-cost technologies with traditional techniques to create large-format sculptures. First, the three-dimensional digitalization and 3D modelling of three statues, belonging to the Cycladic art, is carried out and the raw form is built by stacking foam plates cut with a milling machine. Then, the statuette is worked on until the final shape is achieved. Finally, three procedures are described that have been used to turn the sculptures into a definitive material. One sculpture is made by solid filling, another is filled in two halves to achieve a hollow work, and finally the cement is applied directly to the foam sheets, thus eliminating the need for a mould.
\end{abstract}

\section{Keywords}

large-format sculpture, enlargement, 3D technologies, digitalization, low cost

\section{Introducción}

Las técnicas de creación tradicional de esculturas de gran formato son la talla en piedra, mármol o madera de una obra que normalmente incluye una minuciosa preparación y modelos a tamaño real para tomar medidas (Penny, 1993). Por otro lado, existe la creación de esculturas por moldes que requiere, primero, de un modelo en arcilla que a continuación se convierte en material duradero a través de un proceso complejo (Ward, 2008). Para hacer una escultura de gran formato, normalmente se comienza con un modelo creado por el artista a una escala manejable por una sola persona. Una vez terminado, se procede a reproducirlo a gran tamaño con varios materiales, comúnmente arcilla o cera. Este proceso es denominado ampliación (Barrie, 1992). Para crear una escultura a gran formato, primero es necesario construir un soporte interno, llamado armazón, muchas veces de metal soldado, que es capaz de soportar todo el peso que se le vaya a añadir (Langland, 1999).

Para ampliar una escultura existen varios métodos. Se puede hacer a ojo, mediante dos cuadrículas, una al tamaño de la escultura ya modelada y la segunda al tamaño que se desea ampliar la obra. Funciona, mirando por un punto fijo y comparando las siluetas de ambos modelos. También existe el método de la rejilla en el suelo. Donde se usan dos rejillas, una al tamaño de la obra y la otra al tamaño que se desea ampliar, y se fijan puntos en cada una para obtener la medida (fig. 1a). Estos métodos son de bajo coste, pero requieren grandes habilidades escultóricas. La herramienta tradicional más utilizada para copiar o agrandar esculturas es el puntómetro, que consta de una pluralidad de barras de metal y articulaciones que se pueden colocar en varias orientaciones señalando un punto y luego se fija (fig. 1b). Permite medir tantos puntos como sea necesario y consigue resultados muy detallados (Schodek, 1993). 


\section{artnodes}

https://artnodes.uoc.edu

Tecnologías de fabricación digital de bajo coste aplicadas a la construcción de esculturas de gran formato

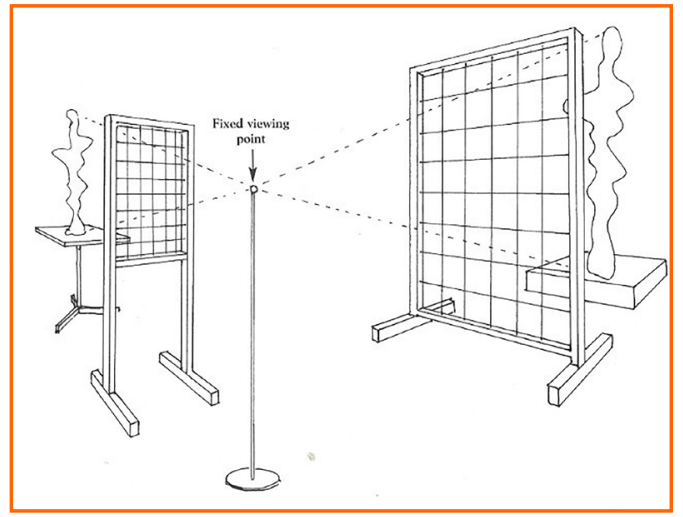

Figura 1a. Método mediante dos cuadrículas para ampliar una escultura (Fuente: Langland, 1999)

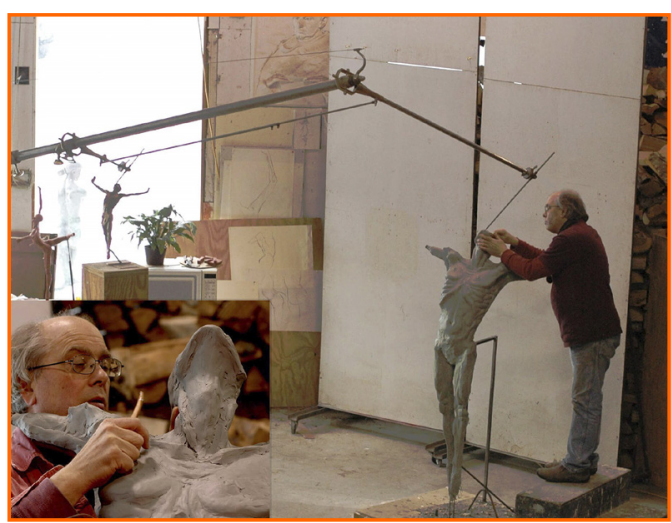

Figura 1b. Puntómetro tradicional (Fuente: andrewdevries.com/)

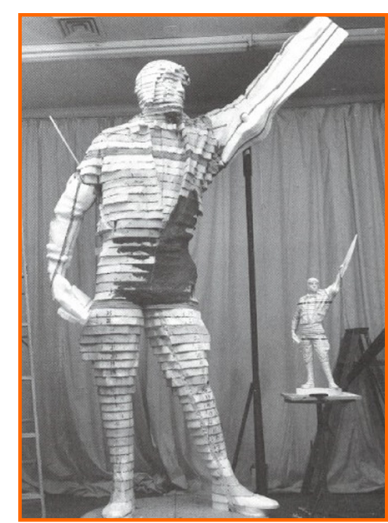

Figura 1c. Técnica de corte y apilamiento por láminas (Fuente: Langland, 1999)
Otro método, documentado por George Lundeen alrededor de 1980, es la técnica de corte por láminas. Consiste en dividir el modelo a escala pequeña de la escultura en láminas de espuma de poliestireno o similar de un cierto grosor. A continuación, para crear la escultura a una escala más grande, se replican las láminas a un tamaño y grosor mayor y se apilan hasta formar una escultura de tamaño ampliado (fig. 1c). Este proceso genera una forma con textura escalonada que es necesaria cubrir mediante material escultórico para conseguir los detalles finales (Langland, 1999). Por último, en los años noventa, se empezó a utilizar las herramientas informatizadas, el escaneo con láser y el tallado con fresadoras informatizadas, aunque difícilmente accesibles y caras en esa época (Caetano-Henríquez, 2012).

En este trabajo se describe un método para ampliar esculturas que combina las tecnologías de fabricación digital con los métodos manuales. Partimos de la digitalización 3D, de bajo coste, mediante fotogrametría de una pieza de pequeño tamaño, pasando por la ampliación y división por secciones horizontales en el ordenador. A continuación, se crea la estructura bruta, a modo armazón interior, mediante el apilamiento de planchas de espuma de poliestireno extruido cortadas con maquinaria de control numérico (fresadora CNC) y apiladas a mano. El siguiente paso es repasar con lijas y añadidos de escayola hasta obtener la forma definitiva y detallada de la escultura. Por último, se transforma el modelo mediante un proceso tradicional a su material definitivo.

\section{Antecedentes}

Las tecnologías de fabricación digital (Jorquera Ortega, 2016) incluyen, por un lado, herramientas informatizadas de diseño como la digitalización 3D mediante escáneres, fotogrametría (Jones y Church, 2020) o modelado 3D y, por otro, la fabricación de objetos mediante impresoras 3D, máquinas de fresado o de corte por control numérico (CNC) (de la Torre-Cantero, Saorín, Meier, Melián Díaz y Alemán, 2015).
Actualmente, en las empresas de producción escultórica se están incorporando las nuevas tecnologías de fabricación digital para abaratar 0 acelerar la elaboración de las obras artísticas de gran formato. Para ello, los artistas crean una escultura a un tamaño manejable para una persona y mediante un escáner de alta resolución se recoge un modelo 3D digital exacto de esa escultura. A continuación, se utiliza el modelo 3D obtenido para hacer una copia, ampliación o reducción de la escultura en formato digital (Form, 2019; Scansite, 2019; Artec3D, 2019). Debido a la limitación de tamaño y tiempo es casi imposible fabricar esculturas de gran formato en una impresora 3D estándar (Liu, 2019). Para la fabricación a gran formato, en el ámbito profesional se suele utilizar fresadoras de cuatro ejes que esculpen con herramientas informatizadas en bloques de material blando como el poliestireno. Otra posibilidad para fabricar un objeto digitalizado es dividirlo en secciones planas y cortar mediante fresadoras dichas secciones en planchas de poliexpán para, a continuación, apilarlas. Esto deja una textura de capas en la obra final que hace necesario retocarla, pero es una manera barata que no necesita maquinaria avanzada para construir esculturas de gran formato (Platero Cremades, 2017).

En nuestro caso proponemos un proceso para crear una escultura de gran formato mediante técnicas de fabricación digital accesibles, sencillas y de bajo coste. Las herramientas que se sugieren pueden ser accesibles para pequeñas empresas de creación escultórica, así como centros universitarios. Por un lado, se explica el proceso de crear la escultura, a gran formato, con planchas de espuma de poliestireno extruido de alta densidad a partir de un modelo a pequeña escala. Esto elimina el complejo proceso de construir un armazón interno mediante hierro soldado u otros materiales pesados sobre el que se modela la figura con arcilla 0 similar. Por otro lado, se explican tres procesos diferentes de cómo convertir la escultura en su material definitivo mediante procesos escultóricos tradicionales. Se llega a la conclusión de que la manera más rápida y barata es trabajar directamente sobre la forma bruta de planchas apiladas, aplicando una capa del material escultórico final. 


\section{artnodes}

https://artnodes.uoc.edu

\section{Materiales y métodos}

Las esculturas que se utilizan para trabajar en este proyecto pertenecen al arte cicládico, que surgió en las islas del mar Egeo durante el 3000 a.C. al 2000 a.C. Las civilizaciones que las habitaron produjeron una serie de figuras humanas talladas en mármol blanco puro y que son las representaciones artísticas más antiguas encontradas hasta ahora del arte griego (Hartt, 1989). Este proyecto está financiado por el grupo empresarial Melisofi Consulting S.A. para el proyecto concreto Arts Lifestyle \& Shopping Tenerife situado en el sur de la isla de Tenerife, Canarias. El encargo fue realizado por un grupo de escultoras y escultores y el Laboratorio de Fabricación Digital de la Facultad de Bellas Artes de la Universidad de La Laguna.

A continuación, se describe el proceso por el cual se han elaborado tres esculturas de gran formato, partiendo de estatuillas de pequeño formato del arte cicládico, uniendo las tecnologías de fabricación digital de bajo coste con las técnicas escultóricas tradicionales.

\subsection{Digitalización}

Para empezar, se ha trabajado con tres modelos de referencia, que se denominaron: El pensador ( $5 \times 6 \times 5 \mathrm{~cm})$, Lady II (6 × $5 \times 10$ $\mathrm{cm})$, proporcionadas por la entidad financiadora, y, por último, $\mathrm{La}$ maternidad, cuyo modelo se ha creado mediante un programa de modelado 3D a partir de una única imagen fotográfica.

El primer paso ha sido la digitalización 3D de dichas piezas. La digitalización de las dos primeras piezas se realizó mediante el procedimiento de fotogrametría. Con esta técnica, es posible la obtención de un modelo tridimensional a partir de un grupo de fotografías que registran el objeto en su totalidad, desde diversos puntos de vista. El software utilizado en este proyecto es Agisoft Photoscan, un programa con un precio accesible y de curva de aprendizaje muy rápida. Sin embargo, también se pueden emplear programas gratuitos con un funcionamiento muy similar como, por ejemplo, Autodesk Recap Photo.

Primero, se realiza una media de 70 imágenes por cada pieza escultórica mediante la cámara Canon EOS 450D con una óptica de 50 $\mathrm{mm}$. Las tomas se organizan por anillos en torno a la pieza que deben cubrir el mayor número posible de puntos de vista. A continuación, el programa ubica automáticamente cada una de las imágenes realizadas en el espacio y se genera la nube de puntos (fig. 2a). Por último, el programa construye una malla poligonal que se exporta en formato .OBJ, un estándar en la exportación de archivos 3D.

En el caso de que la escultura sea difícil de digitalizar mediante fotogrametría o de no disponer de un modelo, como sucede en la pieza Ilamada La maternidad, es posible el modelado 3D directo de la pieza a partir de imágenes de referencia. Aunque existen programas gratuitos de modelado 3D como Blender, Sculptris o Meshmixer, en este caso el software utilizado para la creación del modelo 3D fue ZBrush, de la empresa Pixologic (fig. 2b). Es una aplicación especializada en el modelado 3D orgánico que ha sido desarrollada con una interfaz que trata de replicar una experiencia de modelado con arcilla, de tal manera que se genera la ilusión óptica de estar manipulando barro. Aunque también ofrece la posibilidad de modelado por geometrías.

Debido a las características de las esculturas cícladas, sencillas y simétricas, es posible realizar una interpretación a partir de una sola imagen. Debido a que el modelo final iba a servir como estructura interna sobre la que se aplica directamente una capa del material definitivo, se usa un procedimiento en el modelo digital para reducir todo el perímetro unos centímetros. Esto se lleva a cabo mediante una herramienta común que se encuentra en muchos programas de modelado 3D llamado offset, esa acción reduce en perímetro cada una de las caras a una equidistancia uniforme (fig. 2c). Es decir, que genera una cara interna idéntica a la exterior, pero escalada según el grosor deseado.

\subsection{Construcción del armazón interior ligero}

Una vez que se obtienen los modelos digitales, se procede a construir la escultura a gran formato mediante planchas de espuma de poliestireno extruido de alta densidad $\left(30-40 \mathrm{~kg} / \mathrm{m}^{3}\right)$ de $30 \mathrm{~mm}$ de grosor. Son planchas ligeras de un coste reducido, resistentes al agua y se suelen utilizar como aislante térmico en la construcción de edificaciones. Mediante este proceso se obtiene una forma aproximada a modo de armazón, de textura escalonada que a continuación se

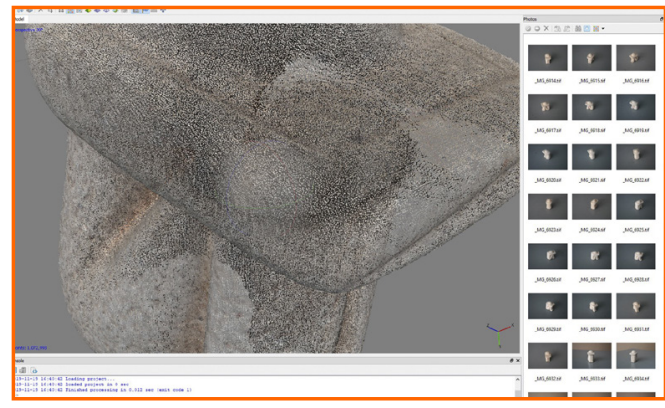

Figura 2a. Nube de puntos de coincidencia a partir de las zonas de solape compartidas en las distintas imágenes en el programa Agisoft Photoscan

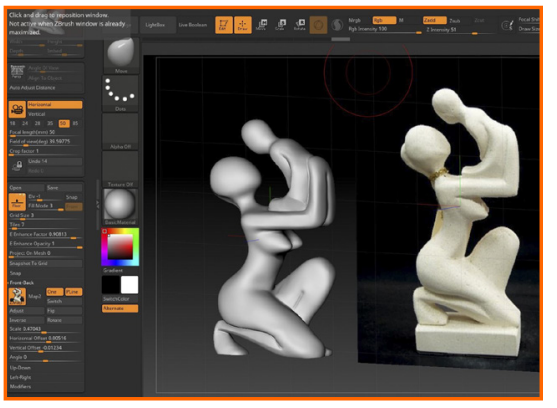

Figura 2b. Programa de modelado 3D ZBrush, modelado de la escultura La Maternidad a partir de una fotografía

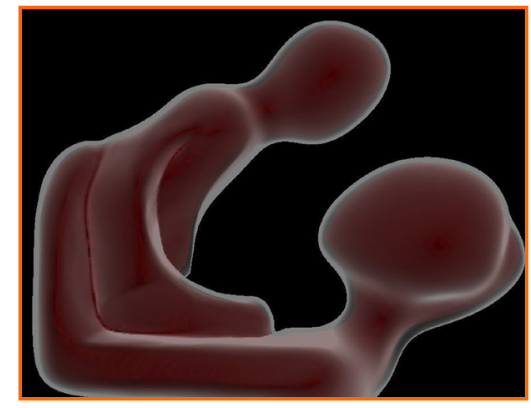

Figura 2c. Aplicación del comando offset en el programa ZBrush para reducir el perímetro del modelo 


\section{artnodes}

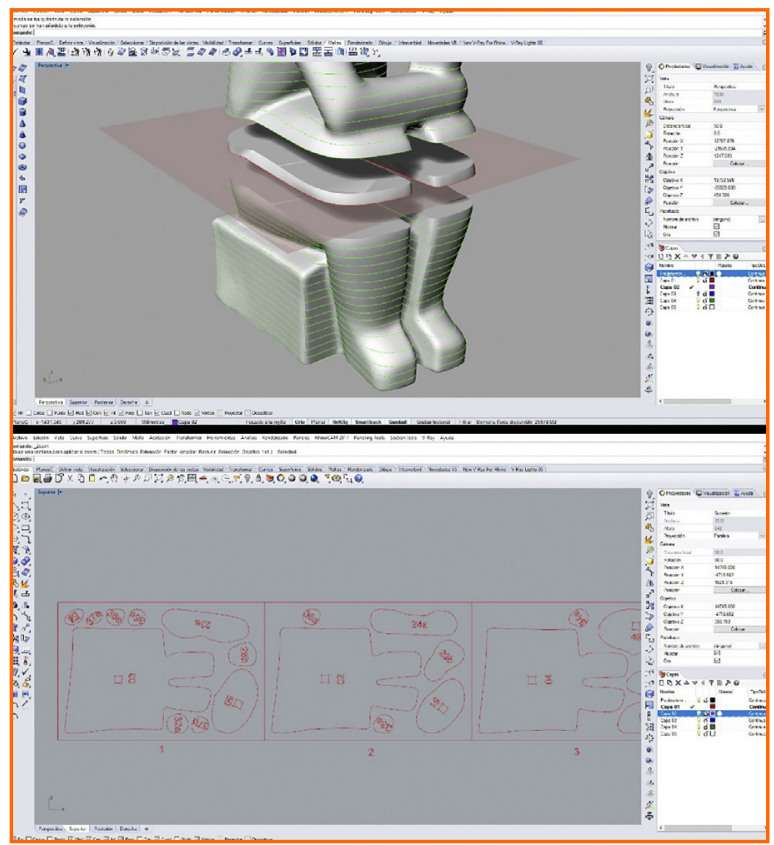

Figura 3a. Programa Rhinoceros 5 para convertir el modelo 3D en archivos para cortar con una fresadora

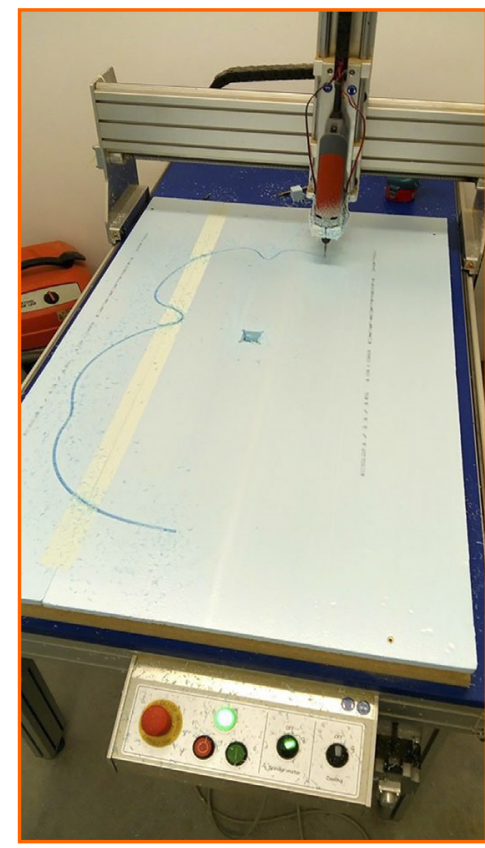

Figura 3b. Corte de las planchas de poliestireno extruido

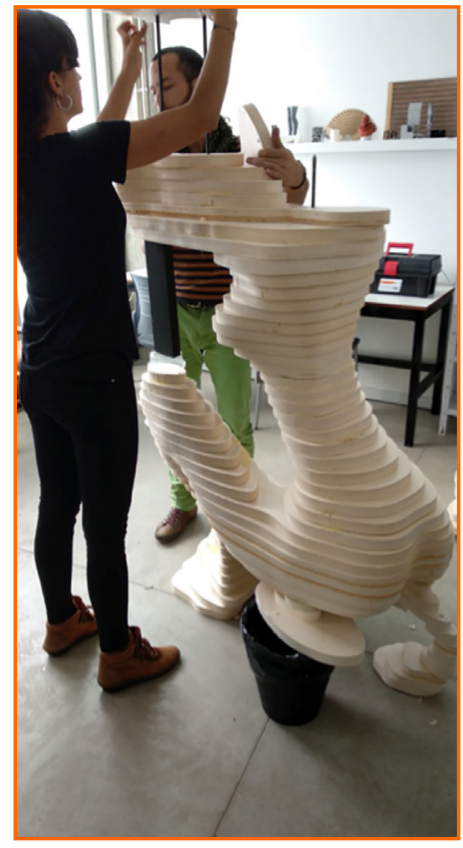

Figura 3c. Apilamiento para reconstruir la obra debe retocar mediante sustracción por abrasión y añadidos de materia para conseguir la forma definitiva.

Para poder construir las esculturas por láminas, el primer paso es laminar la malla 3D en secciones del tamaño y grosor adecuados. Esto son operaciones automáticas en los programas de modelado 3D. Existen programas gratuitos como Slicer de Autodesk Fuison 360 que realizan esta operación en sencillos pasos. El resultado se puede exportar tanto en planchas tridimensionales individuales, en formatos PDF o en archivos DXF que son los adecuados para cualquier máquina fresadora o de corte CNC.

Se utiliza el programa Rhinoceros 5 para convertir los modelos tridimensionales en archivos para cortar con una fresadora CNC (fig. 3a). También se añade un hueco como eje central para superponer cada sección en el lugar correcto una encima de otra. Con posterioridad, cada una de estas líneas se corta con la fresadora CNC sobre las planchas de poliestireno extruido de $30 \mathrm{~mm}$ de espesor (fig. 3b). Además, el programa enumera cada plancha para cortar, para facilitar el montaje posterior. Una vez terminadas las láminas fresadas y enumeradas se procede a la superposición y pegado de cada una de ellas teniendo como referencia un eje central (fig. 3c).

\subsection{Acabado de la escultura}

Obtenido el volumen en poliestireno extruido y retocado con escayola, se realiza un vaciado escultórico siguiendo las técnicas tradicionales de moldeado, para la obtención de la escultura en gran formato en el material definitivo. Se utilizaron tres métodos diferentes, uno para cada una de las esculturas. Para la obra El pensador, se realiza un molde fabricado en diferentes fragmentos diseñado para la forma concreta del volumen que se va a reproducir que se rellena en macizo. La escultura Lady II se hace con un molde bivalvo de partes longitudinales para realizar el vaciado a molde abierto. De este modo, se obtiene una pieza hueca. Por último, en la obra La maternidad, se evita el molde, realizando el volumen por superposición de una capa de material definitivo directamente sobre el núcleo de poliestireno.

\subsubsection{Escultura 1: El pensador}

La pieza El pensador parte de un modelo referencial de pequeño formato de $5 \times 6 \times 5 \mathrm{~cm}$, para reproducirlo a un tamaño de $120 \times 144$ $x 120 \mathrm{~cm}$. Se realiza un vaciado con una mezcla de cemento blanco y marmolina de diferentes granulometrías $(0,5-1,2)$.

Obtenida la forma fiel y con el estuco de escayola aplicado (fig. 4a), se le administra desmoldeante, a base de una solución conformada por $1 / 3$ de gomalaca en escama y agua, respectivamente. El diseño de su molde es una división en siete cuartos seccionados verticalmente y uno horizontal en la parte superior que reproduce el área a modo de tapa. El material utilizado para reproducir el molde es escayola Alfamolde, más resistente que la escayola común. A base de capas proyectadas manualmente, se va conformando el grosor del molde a secciones de $5 \mathrm{~cm}$ aproximadamente.

Fabricadas las piezas del molde, se desmonta para extraer el modelo interno (fig. 4b). A continuación, se procede a limpiar y poner desmoldeante en la zona que será la superficie en contacto con el material definitivo. En este caso, se impregna de una solución realizada por $40 \%$ de aceite de oliva, $40 \%$ de jabón líquido denso y 


\section{artnodes}

https://artnodes.uoc.edu

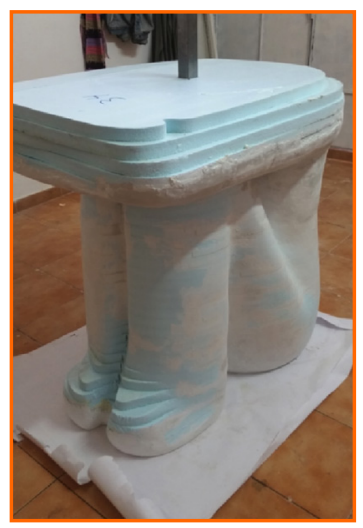

Figura 4a. Trabajo manual de tallado del conjunto y trabajo de superficie

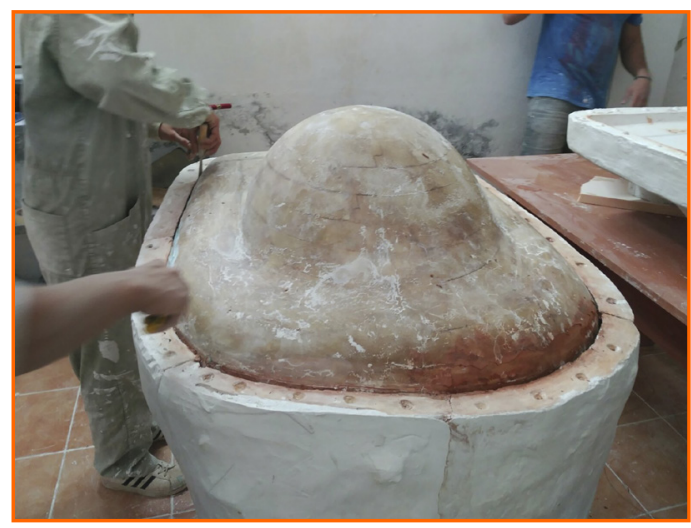

Figura $4 \mathrm{~b}$. Fabricadas las piezas del molde, se procede a desmontarlas para extraer el modelo interno

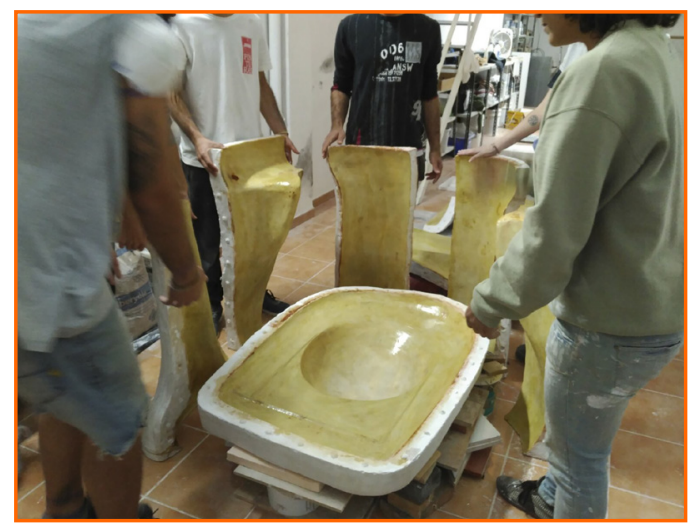

Figura 4c. Molde de 7 piezas limpio y con desmoldeante en la zona que será la superficie en contacto con el material definitivo
$20 \%$ de agua. A continuación, comienza la fase de ensamblaje de los fragmentos del molde (fig. 4c). Este conjunto es sellado con estopa y escayola en todas las juntas, además de cerrado con alambre para evitar que el vertido de cemento ejerza presión sobre el molde. También se realiza una estructura metálica a modo de armazón interno para evitar que los movimientos produzcan fisuras en la masa y, en consecuencia, roturas en la pieza. Seguido, se procede al vertido del material, cemento blanco y marmolina de diferentes granulometrías $(0,5-1,2)$ de $1 / 3$ partes y con una proporción de agua al $45 \%$. De este modo, se ha generado un volumen de aproximadamente unos $600 \mathrm{~kg}$ de peso. Finalmente, se despieza, se voltea y mediante procedimiento manual y abrasivos mecánicos se repasan las imperfecciones y se procede al lijado y pulido de la superficie hasta obtener el acabado requerido.

\subsubsection{Escultura 2: Lady II}

La pieza Lady //parte de un modelo referencial de pequeño formato de $6 \times 5 \times 10 \mathrm{~cm}$, para reproducirlo a un tamaño de $96 \times 80 \times 160 \mathrm{~cm}$. Tiene una morfología de carácter estilizado y un perfil vertical. Por ello, se procede a realizar un molde bivalvo con solo una línea divisoria que la secciona longitudinalmente (fig. 5a). En este caso, al ser el poliestireno un material degradable con acetona, se ha podido disminuir el número de partes del molde. Una vez realizadas ambas piezas del molde, se procede a obtener lo que sería un modelo perdido. Se vierte acetona sobre el modelo de poliestireno y este se va desintegrando, disminuyendo su volumen y facilitando el desmoldeo de las piezas (fig. 5b).

Una vez limpio de restos de poliestireno y repasadas las imperfecciones obtenidas de los fragmentos del molde, se realiza el vaciado, en este caso a molde abierto. Una vez aplicado el desmoldeante en el interior de las piezas del molde, se procede, a modo de capas, a generar el grosor de la pieza definitiva. La primera capa se realizada aplicando el material de cemento blanco y marmolina de granulometría $0,5 \mathrm{~mm}, 1 / 3$ respectivamente y una proporción de agua al $30 \%$. Se realiza por procedimiento de impacto, es decir, proyectando el material para que no quede aire entre pieza y molde. Las capas sucesivas se van realizando por mecanismos manuales a base de espátula y broncha, intercalando capas de fibra de vidrio Mat para obtener mayor dureza en la masa. Una vez repetido el procedimiento en las dos valvas y obtenido aproximadamente $9 \mathrm{~cm}$ de espesor, se desmoldean las partes. Se procede ahora al montaje de las dos piezas (fig. 5c), encarándolas

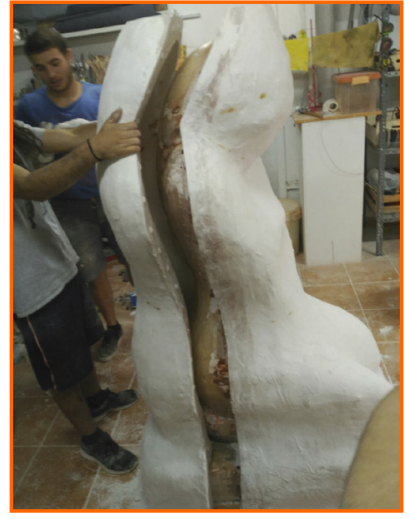

Figura 5a. Molde bivalvo

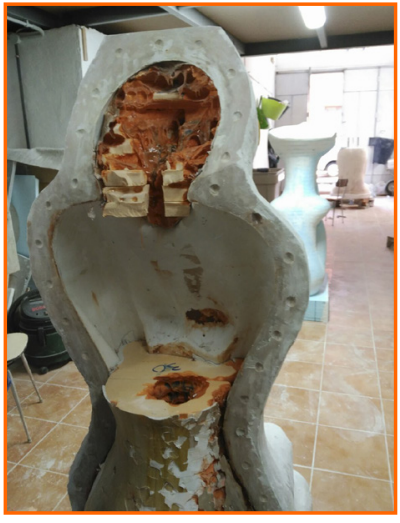

Figura $5 b$. Vertido de acetona sobre el armazón interno para su desintegración

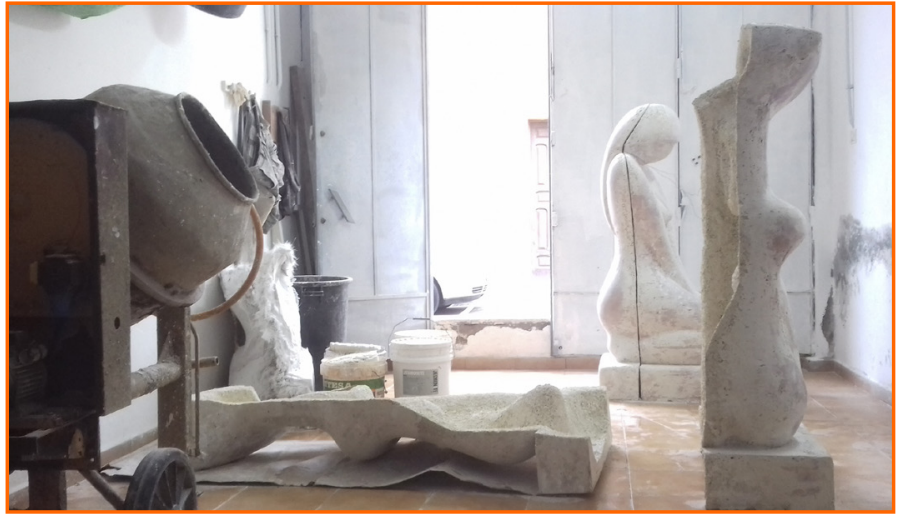

Figura 5c. Montaje de ambas piezas 


\section{artnodes}

https://artnodes.uoc.edu en la posición correcta y aplicando adherente Sikaflex, un adhesivo de poliuretano multiusos y sellador de juntas elástico, en la superficie en contacto. Se refuerza con la misma mezcla del vaciado, tratando su aspecto superficial. Finalmente se lija y se pule la superficie dando el aspecto acabado a la escultura.

\subsubsection{Escultura 3: La maternidad}

La pieza La maternidad parte de una imagen como referencia y se reproduce al tamaño de $220 \times 70 \times 80 \mathrm{~cm}$. En esta escultura se establece un sistema de operar que facilita el procedimiento de una manera notable. Se optó por eliminar la necesidad de realizar un molde y trabajar in situ, directamente sobre el armazón ligero de poliestireno extruido.

Para ello, una vez obtenido el modelo tridimensional, se realiza la operación de offset (compensación de las distancias), lo que reduce todo el perímetro en $5 \mathrm{~cm}$, dando como resultado el margen para poder aplicar el material definitivo y crear la escultura al volumen requerido. La pieza se envuelve con malla metálica como entramado estructural del material aplicado. Y se sigue un sistema de superposición de capas conformando el grosor de la pieza. Se utiliza un cemento tixotrópico (TxT), un material adherente y compacto de fraguado rápido, tiempo suficiente para ir dándole la forma fiel a modelo definitivo. La mezcla se compone de $2 / 3$, cemento TxT y marmolina (grano 0,5 y 1,2) con una proporción acuosa del 250 $30 \%$ según las densidades necesarias a la hora de operar. Una vez completada la forma, se procede al tratamiento superficial con maquinaria abrasiva y elementos manuales, puliendo la pieza hasta dar con el acabado deseado.

\section{Resultados}

Se han obtenido tres esculturas de gran formato, combinando formas tradicionales de trabajar en esculturas de gran formato con las nuevas tecnologías de modelado y fabricación 3D de bajo coste (fig. 6).

Se han digitalizado los modelos con programas de fotogrametría sencillos e incluso gratuitos. También se pueden digitalizar las esculturas a partir de una fotografía con conocimientos de modelado 3D. El paso de convertir los modelos en archivos que pueden ser recortados mediante fresadoras es casi automático. La elaboración de la estructura interior de una escultura mediante planchas de poliestireno extruido ofrece unos modelos muy ligeros, pero estables y rígidos, sin necesidad de realizar mediciones, siendo, además, manejables por una sola persona. Con el proceso se elimina la necesidad de construir un armazón interno de metal soldado, madera o materiales resistentes que son capaces de soportar todo el peso que se le vaya a añadir.

Se describen tres métodos para convertir los modelos de poliestireno extruido en esculturas definitivas. Dichos procedimientos no difieren mucho de los métodos tradicionales, pero facilitan enorme-
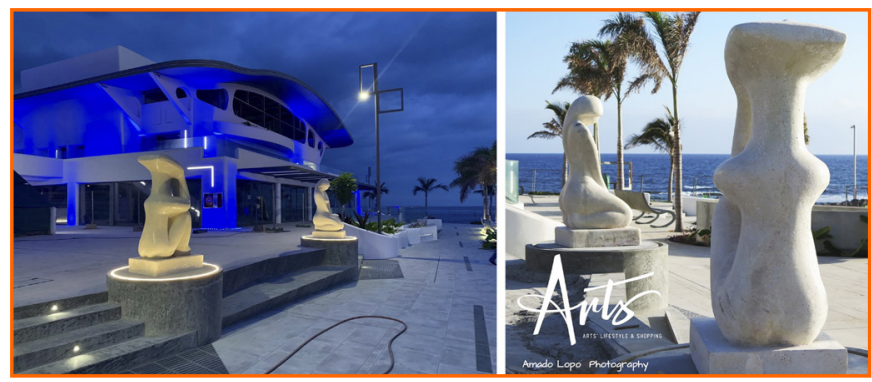

Figura 6. Esculturas terminadas y colocadas en su ubicación definitiva (Fuente: https:// artstenerife.com/)$$
\text { ......... }
$$

mente su elaboración. Se abarata en tiempos, en costes y en estudios complejos de análisis de las formas para poder operar. Se obtienen, al tener una forma bruta interior ligera y manejable, unos volúmenes referenciales que distan mucho de los procesos necesarios, complejos y costosos de conformar las piezas desde cero.

\section{Conclusiones}

Es viable la combinación de técnicas escultóricas tradicionales con las tecnologías de bajo coste de modelado, digitalizado 3D y fabricación digital, siendo posible la reducción de costes en la elaboración de obras de mediano y gran formato. Este estudio de técnicas, procesos, infraestructuras y materiales a gran escala, poco habituales para el moldeado y vaciado, genera una experiencia procesual que abre unas líneas de investigación de gran interés que favorecen la implementación de las tecnologías de digitalización aplicadas al diseño y la fabricación de esculturas.

Aunque en el proceso se utilizan tecnologías de pago, se facilitan alternativas gratuitas y sencillas que no requieren conocimientos avanzados de informática ni aparatos tecnológicos. La digitalización $3 \mathrm{D}$ de las esculturas es muy sencilla con programas de fotogrametría y no se requiere conocimientos avanzados como, por ejemplo, Autodesk Recap Photo para obtener un modelo tridimensional a partir de fotogrametría y el uso de Slicer de Autodesk Fusion 360 para laminar las esculturas.

Una de las herramientas con la que se trabajó durante el proceso es una fresadora CNC; sin embargo, es una maquinaria que no está disponible en todos los talleres. Pero es posible realizar el trabajo sin necesidad de una fresadora, ya George Lundeen (Langland, 1999) descubrió la técnica de ampliar la fabricación de un modelo con planchas mediante la ayuda de un proyector, utilizando la proyección de los recortes en las planchas y recortando mediante herramientas manuales.

La utilización de planchas de poliestireno extruido elimina la necesidad de realizar pesadas estructuras internas que soportan el peso de un molde exterior o el material que se vaya a aplicar. Además, se consigue un modelo de dimensiones exactas sin necesidad de realizar 


\section{artnodes}

continuas mediciones, aunque la textura escalonada que presenta la estructura al ser fabricada por planchas apiladas requiere un trabajo adicional de alisado con superposición de material.

Los tres métodos de convertir las obras en un material duradero y definitivo son viables y se puede elegir según las necesidades y disponibilidades presentes. El primer método que trata de crear una escultura maciza necesita menos trabajo de modelado escultórico, ya que, una vez alisada la superficie, todo el esfuerzo se concentra en crear un molde y vaciarlo con el material definitivo. Sin embargo, se obtiene una escultura pesada de difícil manejo y transporte.

El segundo método, crear una escultura hueca mediante el llenado del molde por capas, elimina el peso de la escultura, pero necesita el esfuerzo de realizar un molde y trabajar su llenado por volteo, además de unir después ambos lados y repasar las juntas. Este método es posible, ya que el armazón interno se puede desintegrar fácilmente con acetona.

Siempre que sea posible, la manera más rápida y barata es realizar una forma interior ligera de poliestireno extruido con una compensación de medidas (offset). A continuación, se compensa ese recorte con la aplicación por capas del material definitivo, obteniendo una escultura ligera, ya que su interior es de poliestireno extruido y se elimina la necesidad de crear un molde. Sin embargo, este proceso requiere más trabajo escultórico de modelado de la escultura de gran formato que puede resultar difícil en esculturas con muchos detalles.

Las técnicas utilizadas en este trabajo son favorables para esculturas de bulto redondo y de formas con pocos detalles, como son las estatuillas del arte cicládico. Sin embargo, para formas más detalladas o complejas, es necesario usar más tiempo y dedicación en el modelado escultórico. En este caso, posiblemente no es viable trabajar directamente con el material definitivo como el cemento sobre una estructura interna, ya que no permite alcanzar los detalles necesarios. Además, es preciso estudiar variedades del proceso y utilizar, por ejemplo, planchas más finas que permiten construir un modelo base con una textura menos escalonada o emplear diferentes productos que permiten más manejo para aplicar como material definitivo.

\section{Futuros trabajos}

En siguientes trabajos se plantea la modificación de los procedimientos para realizar esculturas de gran formato, pero con un nivel mayor de detalle y realismo, así como esculturas de formas más complejas y ramificadas. Este reto no supone grandes cambios en el procesado digital del modelo, pero sí en su adecuación para la obtención de una armadura interior ligera. Por lo que se plantea la exploración en el uso de planchas de distintos materiales que sean susceptibles de ser mecanizados mediante fresadoras CNC o corte CNC por láser, y cuya comercialización se haga en formatos de espesor de entre 3 y $5 \mathrm{~mm}$.

\section{Agradecimientos}

Se agradece la financiación del Proyecto para la digitalización y generación de modelos de reproducción escultórica. Referencia: A17120016 a la empresa Melisofi Consulting S.A. y a la Fundación General Universidad de La Laguna por firmar el contrato de investigación.

\section{Referencias bibliográficas}

Artec3D. 2018. «La escultura se une a la tecnología de escaneo 3D». 7 de mayo. www.artec3d.com/es/news/sculptingmeets-3d-scanning-technology.

Barrie, Bruner F. 1992. Mold Making, Casting \& Patina: For the Student Sculptor. Michigan: Adams, Barrie, Felton and Scott Publishing.

Caetano-Henríquez, Enrique. 2012. «La producción escultórica en la era digital; una tríada entre la industria, la formación y la creación artística contemporánea». ASRI: Arte y sociedad. Revista de investigación, 1, pp. 1-8.

de la Torre-Cantero, Jorge, Jose Saorín, Cecile Meier, Damari Melián Díaz, y Manuel Alemán. M. 2015. «Creación de réplicas de patrimonio escultórico mediante reconstrucción 3D e impresoras 3D de bajo coste para uso en entornos educativos». Arte, Individuo y Sociedad, 27(3), pp. 427-444. D0I: https:// doi.org/10.5209/rev_ARIS.2015.v27.n3.45864.

Form. 2019. Form. https://form.xyz/.

Hartt, Frederick. 1989. Arte, historia de la pintura, escultura y arquitectura. Madrid: Akal.

Jones, Christine A., Elizabeth Church. 2020. «Photogrammetry is for everyone: Structure-from-motion software user experiences in archaeology". Journal of Archaeological Science: Reports, 30. DOI: https://doi.org/10.1016/j.jasrep.2020.102261.

Jorquera Ortega, Adam. 2016. Fabricación digital: Introducción al modelado e impresión 3D. Madrid: Ministerio de Educación, Cultura y Deporte.

Langland, Tuck. 1999. From Clay to Bronce. A studio guide to figurative sculpture. New York: Watson-Guptill Publications.

Liu, Jiamao. 2019. «The Current Application Situation and Development Bottlenecks of 3D Printing Technology in the Field of Sculpture». 3rd International Conference on Art Studies: Science, Experience, Education (ICASSEE 2019). Moscow: Atlantis Press. DOI: https://doi.org/10.2991/icassee-19.2019.59

Penny, Nicholas. 1993. The Materials of Sculpture. New Haven. Yale University Press.

Platero Cremades, F. Javier. 2017. «Propuesta de una metodología para la creación de monumentos falleros basada en la escultura digital». [Trabajo fin de Máster].Máster Universitario en 


\section{artnodes}

https://artnodes.uoc.edu

Tecnologías de fabricación digital de bajo coste aplicadas a la construcción de esculturas de gran formato

Ingeniería del Diseño. Valencia. https://pdfs.semanticscholar. org/a41f/1d5c4cd632a507edf584f3804f57079f925b.pdf.

Scansite. 2019. Scansite 3D. www.scansite.com/art-sculptureand-foundry-applications/.
Schodek, Daniel L. 1993. Structure in Sculpture. Massachusetts: The MIT Press.

Ward, Gerald. 2008. The Grove Encyclopedia of Materials and Techniques in Art. Oxford. Oxford University Press.

\section{CV}
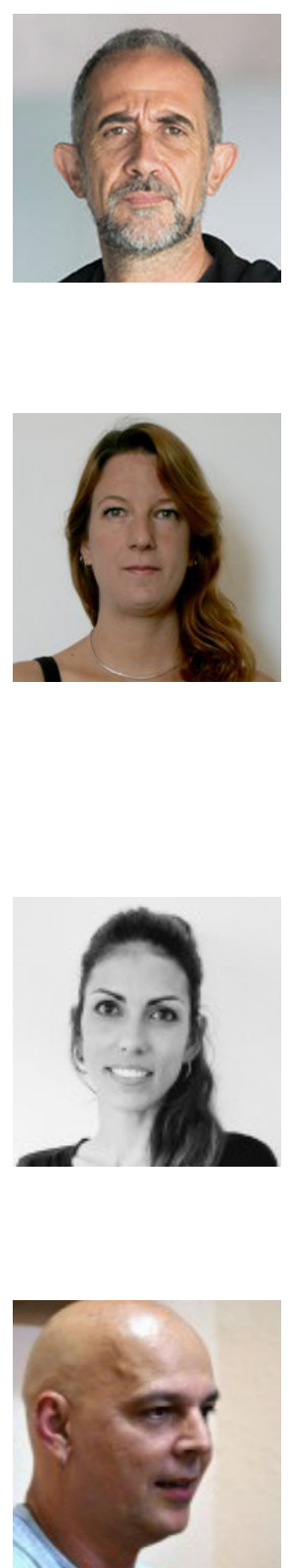

\section{Drago Díaz-Alemán}

Departamento de Bellas Artes, Universidad de La Laguna (España)

madradi@ull.edu.es

Profesor titular del departamento de Bellas Artes, área de Escultura. Fundador y director del Laboratorio de Fabricación Digital de la Universidad de La Laguna (FabLabULL).

\section{Cecile Meier}

Departamento de Bellas Artes, Universidad de La Laguna (España) cemeier@ull.edu.es

Profesora ayudante doctora de la Universidad de La Laguna en la Facultad de Bellas Artes, en el ámbito de la escultura. Su investigación está especializada en el uso de las nuevas tecnologías, los videojuegos, Ios entornos interactivos y la fabricación digital en 3D para la creación de esculturas y el aprendizaje del arte y el patrimonio.

\section{Itahisa Pérez-Conesa}

Departamento de Bellas Artes, Universidad de La Laguna (España) iperecon@ull.edu.es

Profesora del departamento de Bellas Artes, área de Escultura, encargada del taller de escultura y del taller de fundición artística de la universidad.

\section{Esteban Amador-García}

Laboratorio de fabricación digital, Universidad de La Laguna (España) eamadorg@ull.edu.es

Encargado del Laboratorio de Fabricación Digital de la Universidad de la Laguna (FabLabULL). Profesor temporal en el área de Dibujo.

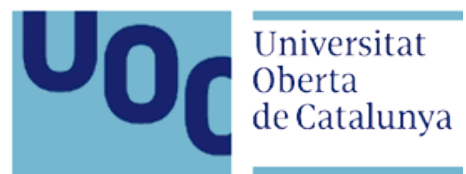

